\title{
POLICY MODEL OF FINANCIAL RESPONSIBILITY AND MEASUREMENT OF BALI WOMEN PERFORMANCE IN SEKAA CINGKREMAN (FEASIBILITY STUDY OF PUBLIC SERVICES)
}

\author{
Ni Ketut Sari Adnyani, Ni Nyoman Mandriani, Ni Kadek Putus Asrini
}

Faculty of Law and Social Sciences

Ganesha Education University

niktsariadnyani@gmail.com

\begin{abstract}
This research is motivated by the problem of service management for members who are recruited as customers based on mutual agreement. In terms of implementation, this is commonly practiced by Balinese women to set aside a portion of their income to be saved (cingkreman). However, if it is identified by a mechanism based solely on agreement, sometimes if there is an dishonest administrator it will have an impact on the losses of its members who are cingkreman customers. The issue of accountability becomes urgent in measuring the financial responsibility of the employees; the management has not been able to measure performance in providing services to sekaa cingkreman members; Cingkreman savings collection which deposits are also based on agreement, in terms of recording still manual and not systematic indicates that financial management has not been organized on a number of occasions the influence of management of all cingkreman has not yet achieved optimal results. In general, this study aims to develop a model of financial accountability and measurement of the performance of Balinese women in sekaa cingkreman (feasibility studies of public services). The method used in this study is a type of research developing a public service policy model among members of the sekaa cingkreman consisting of Balinese women. The policy of financial accountability can be seen from the perspective of Transparency. The techniques of collecting data are observation, interviews and documentation studies, data analysis techniques using qualitative descriptive techniques. The results of this study are models of financial accountability policies that show public service by Balinese women who are members of the sekaa cingkreman.
\end{abstract}

Keywords: policy, model, sekeman cingkreman 


\section{Introduction}

\subsection{Background of the Research}

Bali Province is one of the provinces in which each region has implemented savings (Cingkreman), third-party deposits that are made every working day including Sundays and other holidays, with a nominal amount in accordance with the customer's agreement and withdrawal can only be done when the contract period ends.

Whereas the financial management of Sekaa Cingkreman must be carried out in an orderly manner, in compliance with applicable laws, efficient, effective, transparent and responsible by taking into account justice and compliance. If the financial management of Sekaa Cingkreman is carried out properly in accordance with established regulations, then it will certainly improve performance. But in reality, based on quotes from several respondents who had participated in the Sekaa Cingkreman membership, the performance of Sekaa Cingkreman's financial management was still poor, reflecting the weakness of coordinators and administrators in the regional financial management mechanism. Reflections on the weakness of Sekaa Cingkreman's finances are also an indicator of the potential for corruption to occur in the management process.

Not only financial management that has not been systematic, until now in the aspects of management and financial accountability reflect that the financial management management system has not been productive. an unsystematic bookkeeping system, and its administrators based solely on the appointment of someone as a coordinator causing problems often encountered when administrators fled their members' money. The impact is the loss of customers who are members of the sekaa cingkreman membership. Therefore, based on the analysis of researchers, the problem of accountability becomes the urgency in measuring the financial responsibility of the employees, in terms of the operational feasibility of the collective program, which is based on an agreement in carrying out its activities, does not have an operating procedure standard (SOP); the management has not been able to measure performance in providing services to sekaa cingkreman members; Cingkreman savings collection which deposits are also based on agreement, in terms of recording is still manual and not systematic indicates financial management is not organized in a sekaa cingkreman influence the management of sekaa cingkreman has not obtained optimal performance. Based on the findings of the evidence, it is clear that the financial performance of Sekaa Cingkreman is considered not good. One instrument for assessing the performance of administrators has not been accounted for and has the potential to be misused.

In order to carry out the functions and authority of members' cash management, it is expected that the role of women in Sekaa Cingkreman is better able to explore financial resources specifically to meet the financing needs of its members. With the measurement, analysis and evaluation of data relating to performance, the government can immediately determine various ways to maintain or improve the 
efficiency and effectiveness of an activity and at the same time provide objective information to the public regarding the achievement of results.

Furthermore, Wayne C, Parker (1996: 10) made a research report model on the implementation of women's performance measurement programs conducted by Sekaa Cingkreman in Bali. This model provides a clear status regarding the condition of women's performance measurement programs at Sekaa Cingkreman and looks at how many people actually run this program well. With this observation, it is expected that the management which in fact women will also be more focused in establishing and implementing a performance measurement program that is truly a priority.

\subsection{Formulation of the Problem}

Guidance on the results of the identification of the problem, then the problems in this study are:

1. What is the model of financial accountability and performance of women in supporting the sustainability of Sekaa Cingkreman?

2. What is the influence of the financial accountability policy model on the performance of women in the financial management of Sekaa Cingkreman?

3. How is the influence of the model of financial accountability policies on women's performance in the Sekaa Cingkreman public service?

\subsection{Purpose}

The objectives to be achieved from the implementation of this research are as follows:

1. To find out the model of the policy of financial accountability and women's performance in supporting the sustainability of the Sekaa Cingkreman.

2. To find out the influence between financial accountability and the performance of women in the financial management of Sekaa Cingkreman.

3. To find out the influence between the financial responsibility policy model and the performance of women in the Sekaa Cingkreman public service.

\subsection{Urgency (virtue)}

This activity has a very mutual relationship with various aspects, including: the importance of this research, that: (1) Measuring the performance of women in managing Cingkreman savings can support the improvement of women's quality during decision making. Often the decisions taken by women who are Cingkreman's coordinators are carried out within the limitations of data and various political considerations and pressure from interested parties. The process of developing this performance measurement will enable the Cingkreman group to determine the mission and set goals for achieving certain results. In addition, a method for 
measuring women's performance can also be chosen to see the success of the existing Cingkreman program.

On the other hand, the existence of performance measurement makes the entire Cingkreman group member focus their attention on the results obtained, provide a correct evaluation of the budget implementation and conduct discussions on new program proposals. (2) Performance measurement increases internal accountability. With this performance measurement, accountability will be created automatically throughout the Cingkreman group. The coordinator will then be responsible to the members as a whole. In this case it is recommended to use standard measurement systems such as management by objectives to measure outputs and outcomes. (3) Performance measurement increases public accountability. Although for some parties, reporting on evaluating the performance of women in managing Cingkreman to members is felt to be quite strict, but the publication of this report is very important in the success of a good performance measurement system. Community involvement in Cingkreman management's policy making is getting bigger and the quality of the results of a program is also increasingly being considered. (4) Performance measurement supports strategy planning and goal setting. The process of planning strategies and objectives will be less meaningful without the ability to measure performance and progress program. Without these measures, the success of a program will never be objectively assessed. (5) Performance measurement allows an entity to determine the effective use of resources. Communities are increasingly critical to assess programs that have been designed. Evaluations carried out tend to lead to an assessment of whether the role of women can indeed provide the best service to the community. In this case women also have the opportunity to provide public services while still aiming to provide the best service.

\section{Research methods}

This research was conducted by testing hypotheses to explain certain types of relationships, influences, determining group differences or independence from the characteristics of local governments on the financial performance of local governments.

\subsection{Research Design}

This research is a research on the development of a financial accountability policy model that aims to test the hypothesis proposed by researchers regarding the influence of women's characteristics on the financial performance of Sekaa Cingkreman.

\subsection{Population, and Sampling Techniques}

The population in this study was Sekaa Cingkreman in the province of Bali and the sampling technique was done by judgment-sampling, which means the sample was taken based on predetermined criteria (Jogiyanto, 2005). These criteria include: Samples are Sekaa Cingkreman's financial statements with reasonable exceptions or 
unqualified opinions. In the sample, non-financial data are available, such as the number of Sekaa Cingkreman members.

\subsection{Types and Data Sources}

This study uses secondary data, namely information obtained from other parties. The reason for using secondary data is that this data has data validity guaranteed by other parties so that it is reliable to use in research.

\subsection{Data Analysis}

\section{a. Descriptive Statistics}

Descriptive statistics consist of calculating the mean, median, standard deviation, maximum, and minimum of each sample data (Ghozali, 2006). This analysis is intended to provide an overview of the distribution and behavior of the sample data (Ghozali, 2006).

\section{b. Hypothesis Testing}

Multiple Regression Analysis

This study uses multiple regression models (multiple regression analysis), because consists of one dependent variable and several independent variables. To carry out multiple regression analysis, the following classic assumption tests are needed:

\section{c. Normality Test}

The normality test is used whether in the regression model, the dependent and independent variables have a normal distribution. A good regression model is one that has a normal distribution (Ghozali, 2006). To test data that is normally distributed, a normality test tool will be used, namely one sample KolmogorovSmirnov. Data is said to be normally distributed if the significance of the dependent variable has a significance value of more than 5\%. Good research data are normally distributed.

\section{d. Multicolinerity Test}

Multicollinearity test aims to test whether the regression model found a correlation between independent variables (Ghozali, 2005). A good regression model should not occur between independent correlations. If the independent variables are correlated with each other, then these variables are not orthogonal. Orthogonal variables are independent variables whose correlation values between variables are zero. To detect the presence or absence of multicollinearity in the model, researchers will look at Tolerence and Variance Infusion Factors (VIF) with the tools of the Statistical Product and Service Solution (SPSS) program.

Tolerence measures the variability of selected independent variables that are not explained by other independent variables. So a low Tolerence value is the same as a high VIF value (because of VIF $=1$ / Tolerence). The common cut-off value used to indicate the presence of multicollinearity is the Tolerence value $<0.5$ or equal to the VIF value> 10. If it turns out that there is multicollinearity in the model, the researcher will overcome this with variable transformations. Variable transformation 
is one way to reduce linear relationships between independent variables. Transformation can be done in the form of natural logarithms and first difference or delta forms (Ghozali, 2005).

\section{d. Autocorrelation Test}

The autocorrelation test aims to test whether in the linear regression model there is a correlation between the confounding errors in period $t$ and the interfering errors in the $\mathrm{t}-1$ period (before). If there is a correlation, then there is an autocorrelation problem. Autocorrelation arises because sequential observations over time are related to each other. This is often found in time series data because of "disturbances" in the same individual or group in the next period. In cross section data, the problem of autocorrelation is relatively rare because interference with different observations comes from different individuals or groups. A good regression model is a regression that is free from autocorrelation (Ghozali, 2005). Testing for the presence or absence of autocorrelation problems, researchers will use the Run test with SPSS tools. According to Ghozali (2005), if the value is significant> 0.05 then there is no positive or negative autocorrelation.

\section{Discussion}

3.1. The policy model for financial accountability and women's performance in supporting the sustainability of Sekaa Cingkreman

Explain how the parties involved in the same group of people will behave, because basically they have different interests. Financial responsibility as well as friend provides information regarding financial position, performance and changes in financial position.

The financial responsibility of the employee also shows what management has done, or the management's responsibility for the resources entrusted to it. Sekaa cigkreman financial accountability, will make the information presented becomes more easily understood, has relevance, reliability, and has a high appeal. Conversely, if the financial responsibility of the employee is arranged not based on applicable standards and principles, it can mislead the user.

The success or failure of the cigkreman is very dependent on financial management. Financial management includes funding sources and the use of capital as well as employees.

\subsection{Influence between the model of financial accountability policies and the performance of women in the financial management of Sekaa Cingkreman}

The qualitative characteristics of financial statements are normative measures that need to be realized in accounting information so that they can fulfill their objectives. The following four characteristics are normative prerequisites that are needed so that government financial statements can meet the desired quality, which is relevant, reliable, comparable and understandable. 
1) Relevant

Financial statements can be said to be relevant if the information contained in them can influence user decisions by helping them evaluate past or present events, and predict the future, and confirm or correct the results of their evaluations in the past. Thus, relevant financial statement information can be related to the intended use. Relevant information must meet the specified conditions, namely:

a) Has the benefit of feedback (feedback value). Information allows users to confirm or correct their expectations in the past.

b) Has predictive value Information can help users predict the future based on past results and current events.

c) On time

Information is presented on time so that it can influence and be useful in decision making.

d) Complete

Government financial accounting information is presented as completely as possible, covering all accounting information that can influence decision making by taking into account existing constraints. Information that lies behind each of the main information items contained in the financial statements is clearly stated so that errors in the use of such information can be prevented.

2) Reliable

Financial statements can be said to be reliable if the information contained in them is free from misleading notions and material errors, presents every fact honestly, and can be verified.

a. Can be compared

The information contained in the financial statements will be more useful if it can be compared with the financial statements of the previous period or the financial statements of other reporting entities in general. Comparison can be done internally and externally. Internal comparisons can be made if an entity applies the same accounting policy from year to year. External comparisons can be made if the comparable entity applies the same accounting policy. If a government entity applies accounting policies that are better than the accounting policies currently applied, these changes are disclosed in the period of change.

b. Can be understood

The information presented in the financial statements can be understood by the user and expressed in the form and terms that are adjusted to the limits of understanding of the users. For this reason, the user is assumed to have sufficient knowledge of the activities and operating environment of the reporting entity, as well as the willingness of the user to learn the information in question. 


\subsection{The influence between the policy model of financial responsibility and the performance of women in the public service of Sekaa Cingkreman}

Public services must provide information that can be used by users of financial statements to assess accountability in making economic, social and political decisions. Accountability is defined as the relationship between the party in control and regulating the entity with the party that has formal power over the controlling party. In this case, an accountable third party is also needed to provide a reasonable explanation or reason for all activities carried out and the results of the business obtained in connection with the implementation of a task and the achievement of a particular goal. In the context of organizing sekrung cingkreman, the accountability of all cingkreman cannot be known without the coordinator of sekaa cingkreman informing all staff of his workforce about information relating to the collection of resources and sources of public funds and their use.

Accountability can be viewed from various perspectives. From an accounting perspective, the American Accounting Association states that the accountability of a single entity can be divided into four groups, namely accountability to: (1) Financial resources; (2) Compliance with the rules of law and wisdom administrative; (3) Efficiency and economics of an activity; (4) The results of the program and the activities of the cingkreman that are reflected in the achievement of goals, benefits and effectiveness.

From the perspective of accountability systems, there are several key characteristics of this accountability system, namely: (1) Focusing on results (outcomes); (2) Using several indicators that have been chosen to measure performance; (3) Produce information that is useful for making decisions on a program or policy; (4) Producing data consistently over time; (5) Report results (outcomes) and publish them regularly.

In the study that the researchers did, the focus was that the community wanted to know more about whether the coordinator's role, which was usually represented by the management of the community members chosen as the sekaa cingkreman coordinator, operated economically, efficiently and effectively. Some techniques developed to strengthen accountability systems are strongly influenced by methods widely used in accounting, management and research such as management by objectives, performance budgets, operations research, compliance and performance audits, cost accounting, financial analysis and surveys conducted on the community itself. These techniques are of course also used by all the friends themselves to improve their performance.

\section{Conclusion}

The model of financial accountability policy is successful whether or not all employees are very dependent on financial management. Financial management includes funding sources and the use of capital as well as employees. There is a reciprocal influence between the model of financial accountability policy and the performance of women in Sekaa Cingkreman financial management which is very 
influential for the group cash management. There is a significant influence between the policy model of financial accountability and the performance of women in the public service of Sekaa Cingkreman.

\section{Suggestion}

For related parties, in this case the manager of Sekaa Cingkreman, is expected to be able to provide easy policy support and share experiences in terms of knowledge insights in managing group financial accountability in order to provide public services to members of the collectively initiated Sekaa Cingkreman.

The high creativity of the Group in managing Sekaa Cingkreman is expected to have sustainability in its development to support the transparency of financial accountability while providing public services for members.

\section{References}

Ghozali, Imam. 2006. Aplikasi Analisis Multivariate Dengan Program SPSS. Cetakan IV Penerbit UNDIP.

Jogiyanto. 2005. Metodologi Penelitian Bisnis. Yogyakarta: BPFE.

Perwitasari, Citra. 2010. The Influence of Financial Performance to the Level of Accountability Disclosure of Indonesia's Local Government. Tesis Universitas Sevbelas Maret Surakarta.

Sadjiarto, Adjie. 2000. Akuntabilitas dan Pengukuran Kinerja Pemerintahan. Jurnal Akuntansi dan Keuangan Vol.2 No. 2, Nopember 2000. 